\title{
Dispersion Diagram of Trigonal Piezoelectric Phononic Structures with Langasite Inclusions
}

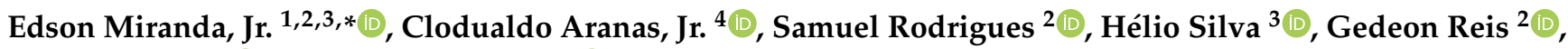 \\ Antônio Paiva ${ }^{2}$ id and José Dos Santos ${ }^{3}$ (D) \\ 1 Federal Institute of Maranhão, IFMA-EIB-DE, Rua Afonso Pena, 174, São Luís CEP 65010-030 , MA, Brazil \\ 2 Federal Institute of Maranhão, IFMA-PPGEM, Avenida Getúlio Vargas, 4, São Luís CEP 65030-005, MA, Brazil; \\ samuel.filgueiras@ifma.edu.br (S.R.); gedeonreis@ifma.edu.br (G.R.); ernandes@ifma.edu.br (A.P.) \\ 3 University of Campinas, UNICAMP-FEM-DMC, Rua Mendeleyev, 200, Campinas CEP 13083-970, SP, Brazil; \\ heliovitorcantanhede@gmail.com (H.S.); zema@unicamp.br (J.D.S.) \\ 4 Department of Mechanical Engineering, University of New Brunswick, Fredericton, NB E3B 5A3, Canada; \\ clod.aranas@unb.ca \\ * Correspondence: edson.jansen@ifma.edu.br
}

Citation: Miranda, E., Jr.; Aranas, C., Jr.; Rodrigues, S.; Silva, H.; Reis, G.; Paiva, A.; Dos Santos, J. Dispersion Diagram of Trigonal Piezoelectric Phononic Structures with Langasite Inclusions. Crystals 2021, 11, 491. https://doi.org/10.3390/cryst 11050491

Academic Editor: Shujun Zhang

Received: 14 March 2021

Accepted: 20 April 2021

Published: 28 April 2021

Publisher's Note: MDPI stays neutral with regard to jurisdictional claims in published maps and institutional affiliations.

Copyright: (C) 2021 by the authors Licensee MDPI, Basel, Switzerland. This article is an open access article distributed under the terms and conditions of the Creative Commons Attribution (CC BY) license (https:// creativecommons.org/licenses/by/ $4.0 /)$.

\begin{abstract}
The dispersion relation of elastic Bloch waves in 1-3 piezoelectric phononic structures (PPnSs) with Langasite $\left(\mathrm{La}_{3} \mathrm{Ga}_{5} \mathrm{SiO}_{14}\right)$ inclusions in a polymeric matrix is reported. Langasite presents promising material properties, for instance good temperature behaviour, high piezoelectric coupling, low acoustic loss and high quality factor. Furthermore, Langasite belongs to the point group 32 and has a trigonal structure. Thus, the 2-D bulk wave propagation in periodic systems with Langasite inclusions cannot be decoupled into $\mathrm{XY}$ and $\mathrm{Z}$ modes. The improved plane wave expansion (IPWE) is used to obtain the dispersion diagram of the bulk Bloch waves in 1-3 PPnSs considering the classical elasticity theory and $D_{3}$ symmetry. Full band gaps are obtained for a broad range of frequency. The piezoelectricity enhances significantly the band gap widths and opens up a narrow band gap in lower frequencies for a filling fraction of 0.5 . This study should be useful for surface acoustic wave (SAW) filter and 1-3 piezocomposite transducer design using PPnSs with Langasite.
\end{abstract}

Keywords: periodic structures; metamaterials; Bragg-type band gaps; anisotropy

\section{Introduction}

The phononic structures (PnSs) [1] are artificial composites designed to achieve special properties, for instance, vibration reduction [2], topologically protected wave propagation [3], acoustic reduction using acoustic black hole [4], wave attenuation using nanostructures [5,6], energy harvesting [7], among others. The PnSs are traditionally composed by 1-D [5,8], 2-D [1,2,6] or 3-D [2] inclusions embedded in a matrix. The acoustic performance of the PnSs depends on the inclusion geometry and material for both 2-D and 3-D cases. The most common geometries of the PnS inclusions are the cylindrical and spherical $[9,10]$. Moreover, the disk-shaped inclusion geometry presents promising properties [11]. There are also the smart PnSs which exploit the piezoelectricity [12-14], piezomagnetism [15] or both [16-18] for mechanical wave manipulation. In this context, the PnSs have also been proposed for transducer design $[19,20]$. Langasite $\left(\mathrm{La}_{3} \mathrm{Ga}_{5} \mathrm{SiO}_{14}\right)$ has been studied in recent years for sensor application [21], because of its unique piezoelectric properties [22,23]. Therefore, Langasite is a potential candidate for the piezoelectric material of transducers using PnSs, thanks to the good material properties, such as good temperature behaviour [23], high piezoelectric coupling, low acoustic loss, high $Q$ factor [24] and mass density compared to quartz [25]. Motivated by these issues, the dispersion diagram of 1-3 piezoelectric phononic structures (PPnSs) with Langasite inclusions in a polymeric matrix is reported for the first time, to the best of our knowledge. In these dispersion diagrams, the formation of full Bragg-type band gaps is observed. The piezoelectricity influences significantly the 
dispersion relation of the 1-3 PPnSs with Langasite. The Lagansite piezoelectric properties, point group 32, trigonal structure and $D_{3}$ symmetry [26] modify the band gap behaviour of the smart PnSs.

\section{Langasite Phononic Structure Modelling}

The improved plane wave expansion (IPWE) method [18,27-29] is used to compute the dispersion diagram of the 1-3 PPnS with trigonal Langasite cylindrical inclusions in a square lattice (see Figure 1).
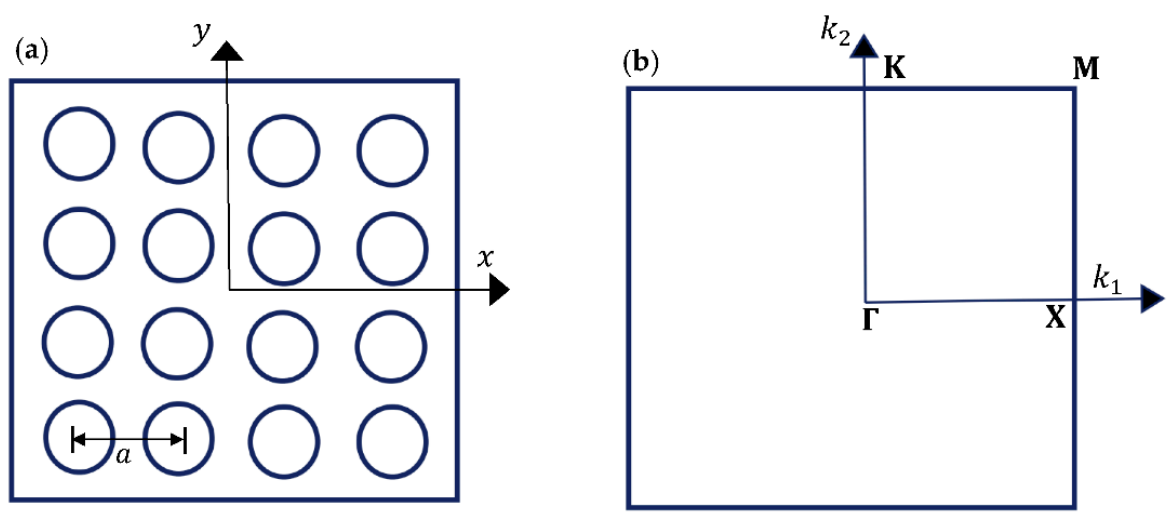

Figure 1. Transverse cross section of the 1-3 PPnS with trigonal Langasite cylindrical inclusions in a square lattice (a). First Brillouin zone for the square lattice (b).

The trigonal structure can be defined as a crystal system that presents some specific classes, i.e., $\overline{3}, \overline{3} \mathrm{~m}, 3,32$ and $3 \mathrm{~m}$, however, only the classes 3,32 and $3 \mathrm{~m}$ have piezoelectricity [30]. In this study, the class 32 (Hermann-Mauguin) $/ D_{3}$ (Schönflies) is considered [26]. It should be pointed out that some studies have already calculated the dispersion diagram of PnSs with trigonal quartz inclusions, with [31] and without [32] piezoelectricity, using the PWE approach. The PWE has the disadvantage of lower convergence than IPWE used in this study [18,27-29]. Moreover, the Langasite inclusions (Figure 1a) are not rotated in this study. The inclusion rotation is an interesting strategy for the tunability of band gaps when anisotropic inclusions are regarded [32].

There are other approaches that can be used to compute the dispersion diagrams, such as the finite element (FE) $[29,33]$ and the wave finite element (WFE) [2] methods. However, the dispersion relation computed by IPWE presents a considerably lower computational cost [29], since it is a semi-analytical approach, and it is not necessary to consider a large number of degrees-of-freedom (DOFs) as with FE and WFE. In this communication, the wave propagation is in the $x y$ plane, the media are linear and there is no electro source. For 1-3 isotropic [6] and transversal isotropic [13,17] PPnSs, the longitudinal-transverse (XY modes) and transverse ( $Z$ modes) vibrations are decoupled, and piezoelectricity influences only the $\mathrm{Z}$ modes. On the other hand, for 1-3 trigonal PPnSs, the $\mathrm{XY}$ and $\mathrm{Z}$ modes are coupled, and piezoelectricity affects both modes. This coupling is observed because of the $D_{3}$ symmetry of the Langasite inclusions, which affects the Van Dyke matrix [26,34]. The IPWE formulation is not derived for brevity.

\section{Simulated Examples}

The physical parameters of Langasite cylindrical inclusions (A) [26] and polymeric matrix (B) [18] are listed in Table 1. The values of the lattice parameter and filling fraction reported in Table 1 were chosen just as a starting point for the simulation. The 441 plane waves to calculate the dispersion diagrams are regarded. The dispersion diagram is plotted in the principal symmetry directions of the first Brillouin zone (FBZ) (Figure $1 \mathrm{~b})$, considering the reduced Bloch wave vector, $\Re(\mathbf{k}) a / 2 \pi$, where $\mathbf{k}$ is the Bloch wave vector, versus the reduced frequency, $\Omega=\Re(\omega) a / 2 \pi c_{t}$, where $\omega$ is the angular frequency 
and $c_{t}=c_{44 B} / \rho_{B}$ is the transverse wave velocity in the polymeric matrix. For the IPWE calculation, it is only considered the values of $\omega \neq 0$ and $\omega \geq 10^{-5}$.

Table 1. Physical parameters of Langasite cylindrical inclusions (A) and polymeric matrix (B).

\begin{tabular}{cc}
\hline Geometry/Property & Value \\
\hline Lattice parameter $(a)$ & $0.022 \mathrm{~m}$ \\
Filling fraction $(f)$ & 0.5 \\
Mass density $\left(\rho_{A}, \rho_{B}\right)$ & $5739 \mathrm{~kg} / \mathrm{m}^{3}, 1150 \mathrm{~kg} / \mathrm{m}^{3}$ \\
Elastic constant $\left(c_{11 A}, c_{11 B}\right)$ & $188.49 \times 10^{9} \mathrm{~N} / \mathrm{m}^{2}, 7.8 \times 10^{9} \mathrm{~N} / \mathrm{m}^{2}$ \\
Elastic constant $\left(c_{12 A}, c_{12 B}\right)$ & $104.07 \times 10^{9} \mathrm{~N} / \mathrm{m}^{2}, 4.7 \times 10^{9} \mathrm{~N} / \mathrm{m}^{2}$ \\
Elastic constant $\left(c_{14 A}, c_{14 B}\right)$ & $14.15 \times 10^{9} \mathrm{~N} / \mathrm{m}^{2}, 0 \mathrm{~N} / \mathrm{m}^{2}$ \\
Elastic constant $\left(c_{44 A}, c_{44 B}\right)$ & $53.71 \times 10^{9} \mathrm{~N} / \mathrm{m}^{2}, 1.6 \times 10^{9} \mathrm{~N} / \mathrm{m}^{2}$ \\
Elastic constant $\left(c_{66 A}, c_{66 B}\right)$ & $42.21 \times 10^{9} \mathrm{~N} / \mathrm{m}^{2}, 1.55 \times 10^{9} \mathrm{~N} / \mathrm{m}^{2}$ \\
Piezoelectric coefficient $\left(e_{11 A}, e_{11 B}\right)$ & $-0.402 \mathrm{C} / \mathrm{m}^{2}, 0 \mathrm{C} / \mathrm{m}^{2}$ \\
Piezoelectric coefficient $\left(e_{14 A}, e_{14 B}\right)$ & $0.13 \mathrm{C} / \mathrm{m}^{2}, 0 \mathrm{C} / \mathrm{m}^{2}$ \\
Dielectric coefficient $\left(\epsilon_{11 A}, \epsilon_{11 B}\right)$ & $0.1737 \times 10^{-9} \mathrm{C}^{2} / \mathrm{Nm}^{2}, 0.0398 \times 10^{-9} \mathrm{C}^{2} / \mathrm{Nm}^{2}$ \\
\hline
\end{tabular}

In an experimental point of view, the proposed 1-3 trigonal PPnSs with Lagasite inclusions can be manufactured in microscale or nanoscale [35] by means of the multiphoton lithography [36,37] or micro-stereolithography [38,39]. Moreover, neglecting size effects, similarly to other studies $[6,13]$, the dispersion diagrams reported in this study $(a=0.022 \mathrm{~m})$ should be the same of those in microsize $(a=22 \mu \mathrm{m})$ or nanosize $(a=22 \mathrm{~nm})$, since the dispersion diagrams are plotted in terms of the reduced frequency. It should be pointed out that it is possible to align the crystallographic axes of the inclusions during the fabrication by means of the Czochralski method [40-42].

Figure 2 shows the dispersion diagrams of the 1-3 PnS with cylindrical Langasite inclusions in a square lattice, without (a) and with (b) piezoelectricity, until a reduced frequency of 3. Two (a) and three (b) full band gaps (FBG) for the cases without and with piezoelectric effect, respectively, can be seen. Therefore, the bulk wave attenuation can be expected between 0.877-1.035 (1st FBG) and 1.101-1.353 (2nd FBG) for the case without piezoelectricity (a) and between 0.7001-0.7045 (1st FBG), 0.9199-0.9332 (2nd FBG) and 1.127-1.407 (3rd FBG) for the case with piezoelectricity (b). The piezoelectricity (b) opens up an additional narrow FBG in lower frequencies and broadens the last one, however, the middle FBG is shortened.

(a)

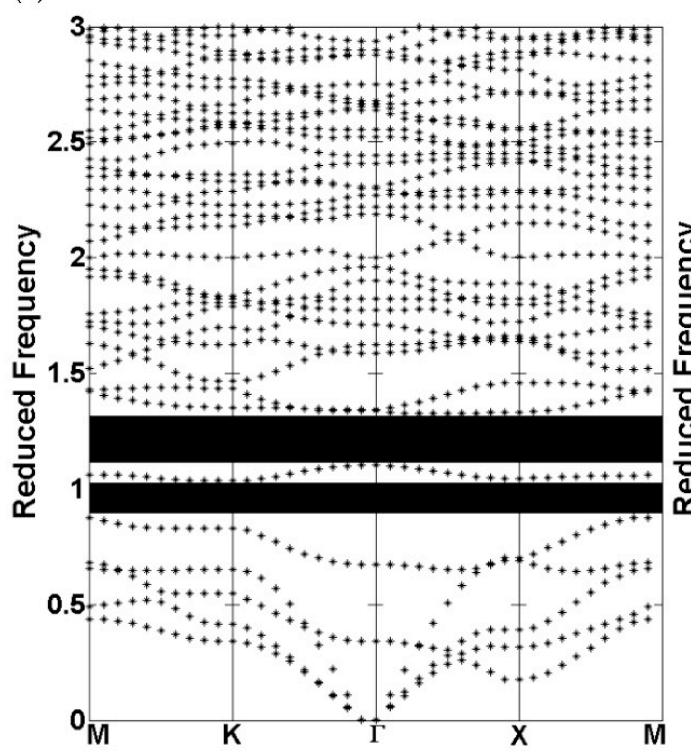

(b)

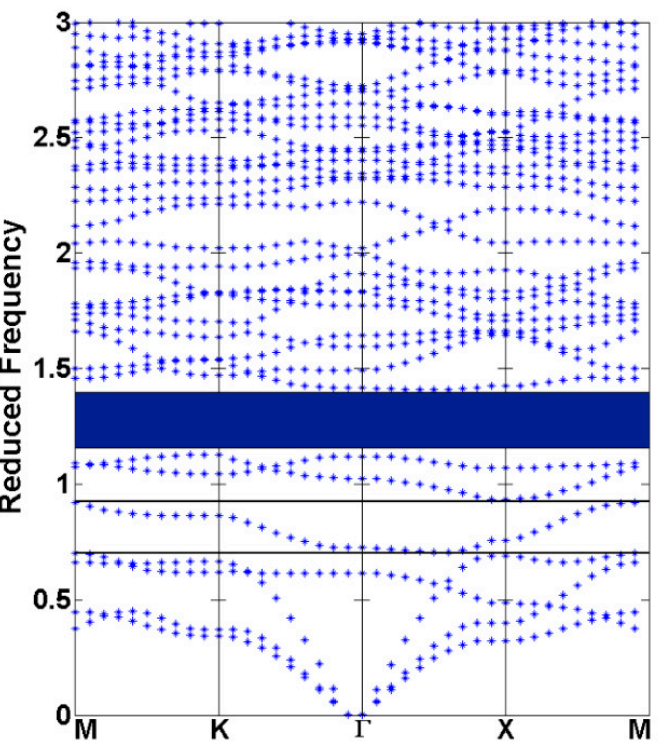

Figure 2. Dispersion diagrams of the 1-3 PPnS with Langasite cylindrical inclusions in a square lattice without (a) and with (b) piezoelectricity. The shaded regions are the full band gaps. 
There is always uncertainty associated with the manufacturing processes [43], thus some of the narrow FBGs observed in Figure $2 b$ could not be opened up to the question of whether uncertainties in the geometric and material parameters are considered [44]. Figure 3 illustrates the dispersion diagram comparison between the cases without (black circles) and with (blue asterisks) piezoelectric effect. When piezoelectricity is considered in 1-3 PPnSs with transversal isotropic cylindrical inclusions in a square lattice, the piezoelectricity affects only the branches ( $Z$ modes) of higher frequencies $[13,17,45]$, shifting them to lower frequencies. In Figure 3, a different behaviour is observed and the branches are dissimilar even for lower frequencies.

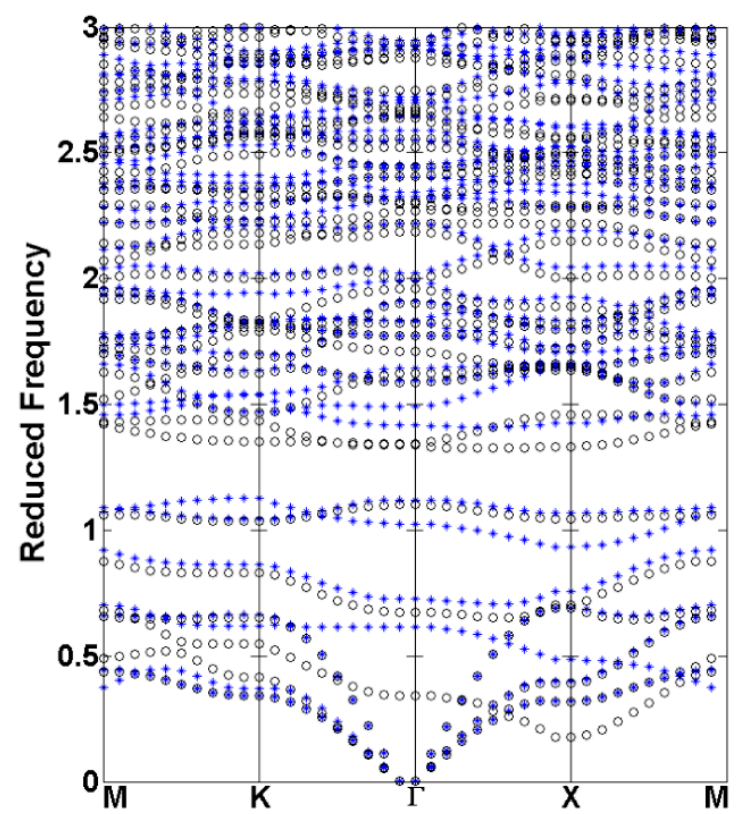

Figure 3. Dispersion diagram comparison of the 1-3 PPnS with Langasite cylindrical inclusions in a square lattice without (black circles) and with (blue asterisks) piezoelectricity.

Shown in Figures 4 and 5 are the wave modes (considering the piezoelectricity) of the first narrow FBG at lower (Figure 4) and upper (Figure 5) edge frequencies (see Figure 2b), i.e., at a reduced frequency of 0.7001 , at $\mathbf{M}$ of the FBZ (Figure 4 ), and at a reduced frequency of 0.7043 , on $\Gamma X$ direction of the FBZ (Figure 5). The displacement field patterns are reported in all directions, that is to say $u_{x}, u_{y}$ and $u_{z}$, in Figures 4 and 5a-c, respectively. At the lower edge frequency of the first FBG (Figure 4), the highest amplitude is observed for $u_{x}$ and the lowest for $u_{z}$, thus the main contribution of this mode is associated with the $x$ component. Moreover, the displacement patterns in Figure 4 are different in all directions. For the upper edge frequency (Figure 5), the $u_{z}$ shows the highest amplitude and $u_{x}$ the lowest one. The wave modes in $y$ and $z$ directions present a similar pattern. The shape of these displacement fields in Figures 4 and 5 is only related to Bragg-type band gaps, however, there are also the wave modes associated with locally resonant band gaps [2,46] for the case of mechanical metamaterials. 


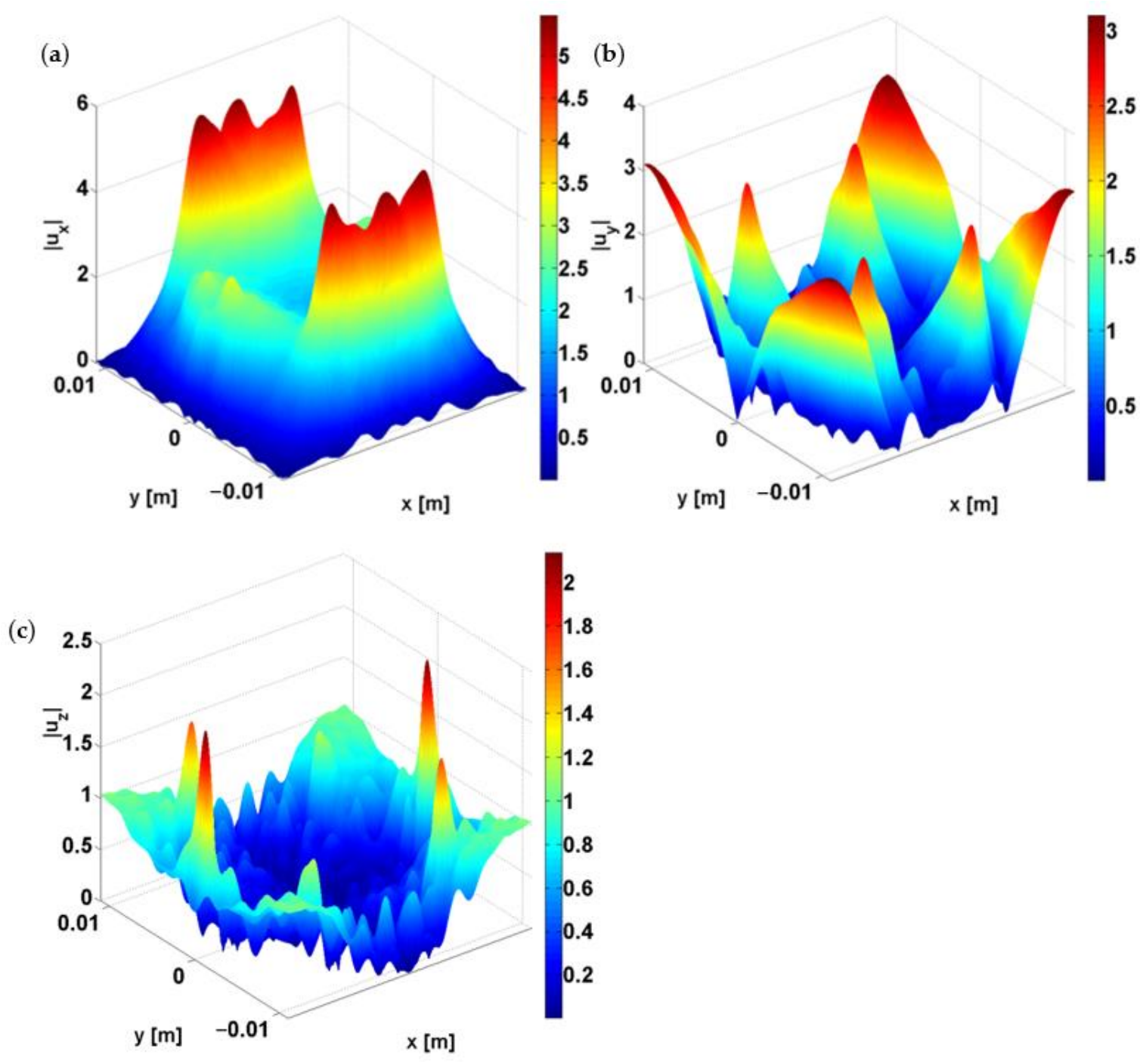

Figure 4. Wave modes (at the lower edge frequency of the first FBG, 0.7001, and at $\mathbf{M}$ of the FBZ) for the 1-3 PPnS with Langasite cylindrical inclusions in a square lattice with piezoelectricity $(\mathbf{a}-\mathbf{c})$.

Figure 6 shows the band gap widths $\left(\Delta \Omega / \Omega_{\mathrm{C}}\right)$ of the first two FBGs without (a) and with (b) piezoelectricity, where $\Delta \Omega$ is the band width and $\Omega_{\mathrm{c}}$ is the centre frequency of the band gap. The piezoelectricity increases the range of filling fraction where the first two FBGs can be opened up. The best behaviour regarding piezoelectric effect (b) is observed between $0.405-0.56$ for both FBGs, with a maximum band gap width at 0.51 . Moreover, without piezoelectricity (a), the higher band gap width is observed for 0.46 and 0.41 considering the first and second FBGs, respectively. Lin and Huang [32] reported a maximum band gap width at a filling fraction of 0.55 considering quartz cylindrical inclusions (without piezoelectricity) in an epoxy matrix with square lattice. They [32] observed that the FBGs are opened up between 0.35-0.6. In general, the first two band gap widths of the 1-3 PPnS with Langasite cylindrical inclusions in a square lattice do not present a typical smooth curve $[6,13,17,18]$. Another issue is that a minor variation of filling fraction changes the band width significantly and sometimes in an unexpected way. Furthermore, the influence of the disorder and shape of Langasite inclusions on the dispersion diagram should be investigated in the future. 

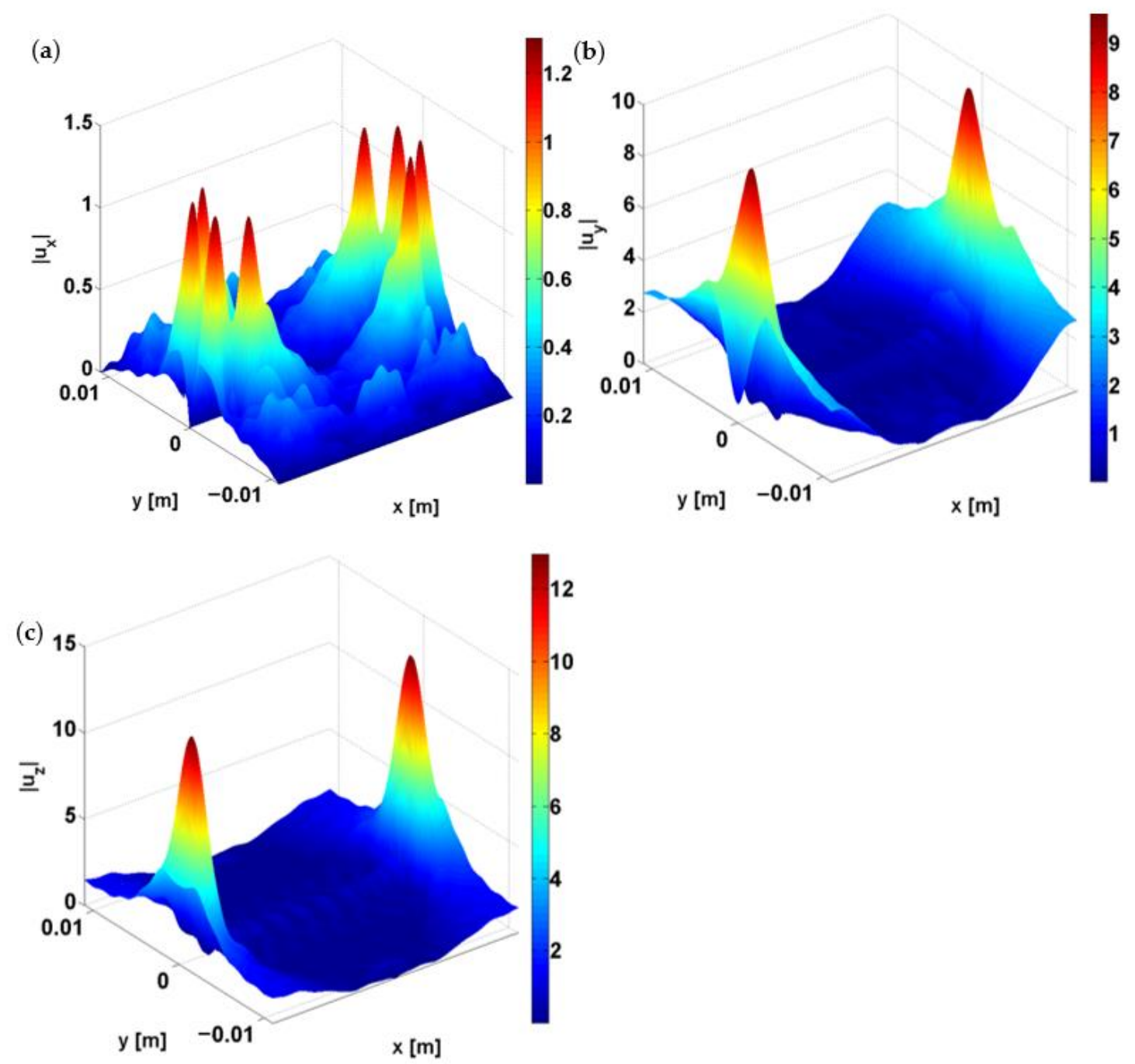

Figure 5. Wave modes (at the upper edge frequency of the first FBG, 0.7043, and on $\Gamma X$ direction of the FBZ) for the 1-3 PPnS with Langasite cylindrical inclusions in a square lattice with piezoelectricity $(\mathbf{a}-\mathbf{c})$.
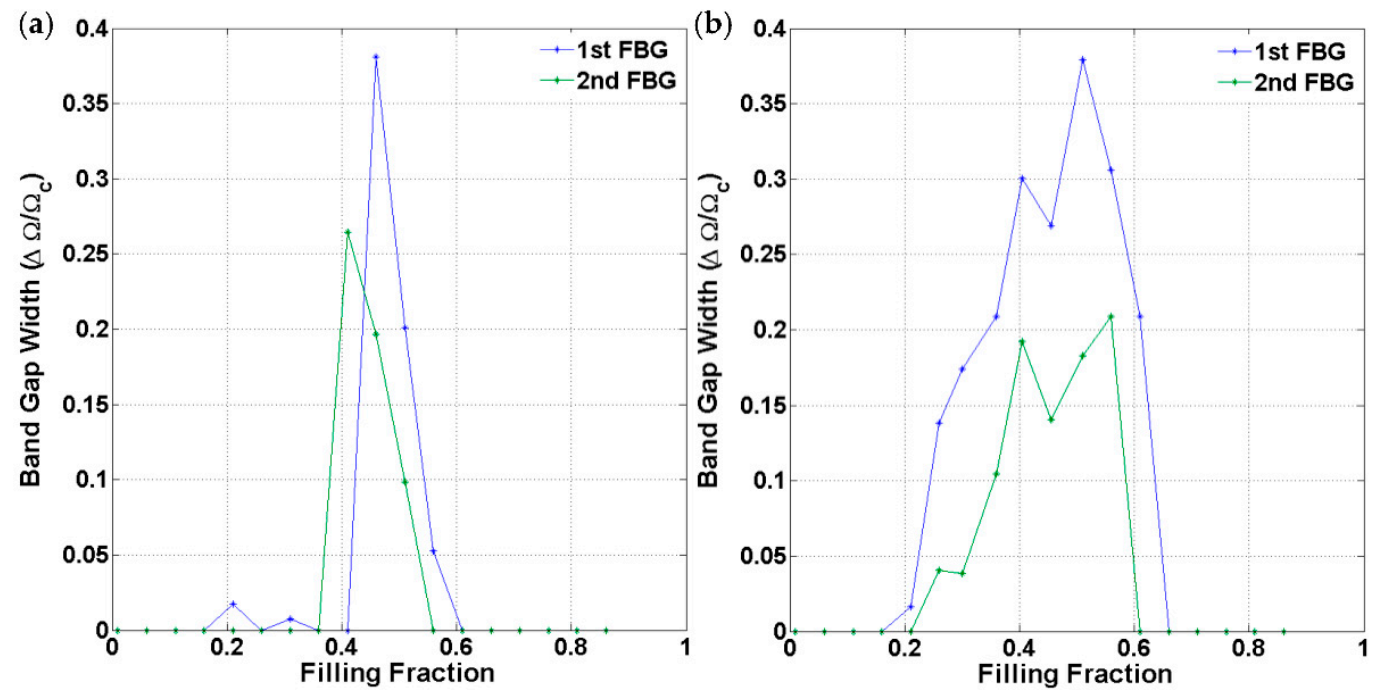

Figure 6. Band gap widths of the 1-3 PPnS with Langasite cylindrical inclusions in a square lattice without (a) and with (b) piezoelectricity, considering only the first two FBGs. 


\section{Conclusions}

The dispersion relation of 1-3 PPnSs is investigated considering Langasite cylindrical inclusions in a square lattice using the IPWE. The 2-D elastic wave propagation in this periodic system with Langasite inclusions is complex, because the $\mathrm{XY}$ and $\mathrm{Z}$ modes are coupled. This coupling exists since the Lagansite presents a trigonal structure, point group 32 and $D_{3}$ symmetry. Full Bragg-type band gaps are opened up for a broad spectrum of frequency. Piezoelectricity broadens the last band gap and creates a narrow band gap in lower frequencies for a filling fraction of 0.5. Moreover, the wave modes in all directions are reported for the edge frequencies of the first band gap for the case with piezoelectricity. The piezoelectric effect enhances the filling fraction range where the FBGs are opened up. The 1-3 trigonal PPnSs with Langasite inclusions enlarge possible applications for the surface acoustic wave (SAW) filter and transducer design.

Author Contributions: Conceptualization, E.M.J.; methodology, E.M.J., C.A.J., S.R., G.R. and A.P.; simulation, E.M.J., H.S. and J.D.S.; writing-original draft preparation, E.M.J. and J.D.S. All authors have read and agreed to the published version of the manuscript.

Funding: The funding received from the Natural Sciences and Engineering Research Council of Canada (NSERC), Canada Foundation for Innovation (CFI), New Brunswick Innovation Foundation (NBIF) and the Harrison McCain Foundation. This research was also funded by Brazilian funding agencies CAPES (Finance Code 001), CNPq (Grant Reference Numbers 313620/2018 and 151311/20200), FAPEMA (Grant Reference Numbers 00857/19, 02730/19, 00824/20 and 00133/21) and FAPESP (Grant Reference Number 2018/15894-0).

Institutional Review Board Statement: Not applicable.

Informed Consent Statement: Not applicable.

Data Availability Statement: Not applicable.

Conflicts of Interest: The authors declare no conflict of interest.

\section{References}

1. Kushwaha, M.S.; Halevi, P.; Dobrzynski, L.; Djafari-Rouhani, B. Acoustic band structure of periodic elastic composites. Phys. Rev. Lett. 1993, 71, 2022-2025. [CrossRef]

2. Dal Poggetto, V.F.; Serpa, A.L. Flexural wave band gaps in a ternary periodic metamaterial plate using the plane wave expansion method. J. Sound Vib. 2021, 495, 115909. [CrossRef]

3. Chen, Y.; Meng, F.; Huang, X. Creating acoustic topological insulators through topology optimization. Mech. Syst. Signal. Process. 2021, 146, 107054. [CrossRef]

4. Tang, L.; Cheng, L. Impaired sound radiation in plates with periodic tunneled Acoustic Black Holes. Mech. Syst. Signal. Process. 2020, 135, 106410. [CrossRef]

5. Qian, D. Bandgap properties of a piezoelectric phononic crystal nanobeam based on nonlocal theory. J. Mater. Sci. 2019, 54, 4038-4048. [CrossRef]

6. Miranda, E.J.P., Jr.; Dos Santos, J.M.C. Band structure in carbon nanostructure phononic crystals. Mat. Res. 2017, 20 (Suppl. 1), 555-571. [CrossRef]

7. Jo, S.-H.; Yoon, H.; Shin, Y.C.; Youn, B.D. A graded phononic crystal with decoupled double defects for broadband energy localization. Int. J. Mech. Sci. 2020, 183, 105833. [CrossRef]

8. Gupta, M.; Ruzzene, M. Dynamics of quasiperiodic beams. Crystals 2020, 10, 1144. [CrossRef]

9. Sharma, G.S.; Skvortsov, A.; MacGillivray, I.; Kessissoglou, N. Acoustic performance of periodic steel cylinders embedded in a viscoelastic medium. J. Sound Vib. 2019, 443, 652-665. [CrossRef]

10. Sharma, G.S.; Skvortsov, A.; MacGillivray, I.; Kessissoglou, N. Sound scattering by a bubble metasurface. Phys. Rev. B 2020, 102, 214308. [CrossRef]

11. Sharma, G.S.; Skvortsov, A.; MacGillivray, I.; Kessissoglou, N. On superscattering of sound waves by a lattice of disk-shaped cavities in a soft material. Appl. Phys. Lett. 2020, 116, 041602. [CrossRef]

12. Wilm, M.; Ballandras, S.; Laude, V.; Pastureaud, T. A full 3D plane-wave-expansion model for 1-3 piezoelectric composite structures. J. Acoust. Soc. Am. 2002, 112, 943-952. [CrossRef] [PubMed]

13. Miranda, E.J.P., Jr.; Dos Santos, J.M.C. Complete band gaps in nano-piezoelectric phononic crystals. Mat. Res. 2017, 20 (Suppl. 1), 15-38. [CrossRef]

14. Sugino, C.; Ruzzene, M.; Erturk, A. An analytical framework for locally resonant piezoelectric metamaterial plates. Int. J. Solids Struct. 2020, 182-183, 281-294. [CrossRef] 
15. Robillard, J.-F.; Bou Matar, O.; Vasseur, J.O.; Deymier, P.A.; Stippinger, M.; Hladky-Hennion, A.-C.; Pennec, Y.; Djafari-Rouhani, B. Tunable magnetoelastic phononic crystals. Appl. Phys. Lett. 2009, 95, 124104. [CrossRef]

16. Wang, Y.-Z.; Li, F.-M.; Huang, W.-H.; Jiang, X.; Wang, Y.-S.; Kishimoto, K. Wave band gaps in two-dimensional piezoelectric/piezomagnetic phononic crystals. Int. J. Solids Struct. 2008, 45, 4203-4210. [CrossRef]

17. Miranda, E.J.P., Jr.; Dos Santos, J.M.C. Evanescent Bloch waves and complex band structure in magnetoelectroelastic phononic crystals. Mech. Syst. Signal. Pr. 2018, 112, 280-304. [CrossRef]

18. Miranda, E.J.P., Jr.; Rodrigues, S.F.; Aranas, C., Jr.; Silva, H.V.C.; Silva, E.S.; Reis, G.S.; Paiva, A.E.M.; Dos Santos, J.M.C. Modelling propagating Bloch waves in magnetoelectroelastic phononic structures with Kagomé lattice using the improved plane wave expansion. Crystals 2020, 10, 586. [CrossRef]

19. Ronda, S.; Aragón, J.L.; Iglesias, E.; Espinosa, F.M. The use of phononic crystals to design piezoelectric power transducers. Sensors 2017, 17, 729. [CrossRef]

20. Ronda, S.; Espinosa, F.M. Design of piezoelectric piston-like piezoelectric transducers based on a phononic crystal. Adv. Appl. Ceram. 2017, 117, 177-181. [CrossRef]

21. Yenuganti, S.; Zhang, H.; Zhang, C. Langasite crystal based pressure sensor with temperature compensation. Sensor Actuat. A Phys. 2018, 281, 108-116. [CrossRef]

22. Beli, A.J.; Comyn, T.P.; Stevenson, T.J. Expanding the application space for piezoelectric materials. APL Mater. $2021,9,010901$. [CrossRef]

23. Zhang, S.; Li, F.; Yu, F.; Jiang, X.; Lee, H.-Y.; Luo, J.; Shrout, T.R. Recent developments in piezoelectric crystals. J. Korean Ceram. Soc. 2018, 55, 419-439. [CrossRef]

24. Zhang, H.; Turner, J.A.; Yang, J.; Kosinski, J.A. Electroelastic effect of thickness mode Langasite resonators. IEEE T Ultrason. Ferr. 2007, 54, 2120-2128. [CrossRef] [PubMed]

25. Choi, G.; Yong, Y.-K. Langatate and Langasite microacoustic gyro sensors. IEEE Int. Ultrason. Symp. 2014, 54, 1480-1483.

26. Heywang, W.; Lubitz, K.; Wersing, W. Piezoelectricity: Evolution and Future of a Technology, 1st ed.; Springer Series in Materials Science: Oldenburg, Germany, 2008.

27. Cao, Y.; Hou, Z.; Liu, Y. Convergence problem of plane-wave expansion method for phononic crystals. Phys. Lett. A. 2004, 327, 247-253. [CrossRef]

28. Xie, L.; Xia, B.; Liu, J.; Huang, G.; Lei, J. An improved fast plane wave expansion method for topology optimization of phononic crystals. Int. J. Mech. Sci. 2017, 120, 171-181. [CrossRef]

29. Dal Poggetto, V.F.; Serpa, A.L. Elastic wave band gaps in a three-dimensional periodic metamaterial using the plane wave expansion method. Int. J. Mech. Sci. 2020, 184, 105841. [CrossRef]

30. Ballato, A. Piezoelectricity: Old effect, new thrusts. IEEE T Ultrason. Ferr. 1995, 42, 916-925. [CrossRef]

31. Wilm, M.; Khelif, A.; Ballandras, S.; Laude, V.; Djafari-Rouhani, B. Out-of-plane propagation of elastic waves in two-dimensional phononic band-gap materials. Phys. Rev. E 2003, 67, 065602(R). [CrossRef]

32. Lin, S.-C.S.; Huang, T.J. Tunable phononic crystals with anisotropic inclusions. Phys. Rev. B 2011, 83, 174303. [CrossRef]

33. Sharma, G.S.; Eggler, D.; Peters, H.; Kessissoglou, N.; Skvortsov, A.; MacGillivry, I. Acoustic performance of periodic composite materials. In Proceedings of the Acoustics 2015 Hunter Valley, NSW Hunter Valley, Australia, 15-18 November 2015.

34. Van Dyke, K.S. Matrices of piezoelectric, elastic, and dielectric constants. J. Acoust. Soc. Am. 1950, 22, 681. [CrossRef]

35. Schnepp, Z.; Mitchells, J.; Mann, S.; Hall, S.R. Biopolymer-mediated synthesis of anisotropic piezoelectric nanorods. Chem. Commun. 2010, 46, 4887-4889. [CrossRef]

36. Gissibl, T.; Thiele, S.; Herkommer, A.; Giessen, H. Two-photon direct laser writing of ultracompact multi-lens objectives. Nat. Photonics. 2016, 10, 554-561. [CrossRef]

37. Malinauskas, M.; Žukauskas, A.; Hasegawa, S.; Hayasaki, Y.; Mizeikis, V.; Buividas, R.; Juodkazis, S. Ultrafast laser processing of materials: From science to industry. Light Sci. Appl. 2016, 5, e16133. [CrossRef]

38. Cui, H.; Hensleigh, R.; Chen, H.; Zheng, X. Additive Manufacturing and size-dependent mechanical properties of threedimensional microarchitected, high-temperature ceramic metamaterials. J. Mater. Sci. 2018, 33, 360-371. [CrossRef]

39. Surjadi, J.U.; Gao, L.; Du, H.; Li, X.; Xiong, X.; Fang, N.X.; Lu, Y. Mechanical metamaterials and their engineering applications. Adv. Eng. Mater. 2019, 21, 1800864. [CrossRef]

40. Bohm, J.; Heimann, R.B.; Hengst, M.; Roewer, R.; Schindler, J. Czochralski growth and characterization of piezoelectric single crystals with langasite structure: $\mathrm{La}_{3} \mathrm{Ga}_{5} \mathrm{SiO}_{14}$ (LGS), $\mathrm{La}_{3} \mathrm{Ga}_{5.5} \mathrm{Nb}_{0.5} \mathrm{O}_{14}$ (LGN), and $\mathrm{La}_{3} \mathrm{Ga}_{5.5} \mathrm{Ta}_{0.5} \mathrm{O}_{14}$ (LGT): Part I. J. Cryst. Growth. 1999, 204, 128-136. [CrossRef]

41. Bohm, J.; Chilla, E.; Flannery, C.; Flöhlich, H.-J.; Hauke, T.; Heimann, R.B.; Hengst, M.; Straube, U. Czochralski growth and characterization of piezoelectric single crystals with langasite structure: $\mathrm{La}_{3} \mathrm{Ga}_{5} \mathrm{SiO}_{14}(\mathrm{LGS}), \mathrm{La}_{3} \mathrm{Ga}_{5.5} \mathrm{Nb}_{0.5} \mathrm{O}_{14}(\mathrm{LGN})$, and $\mathrm{La}_{3} \mathrm{Ga}_{5.5} \mathrm{Ta}_{0.5} \mathrm{O}_{14}$ (LGT) Part II. J. Cryst. Growth. 2000, 216, 293-298. [CrossRef]

42. Zhang, X.; Loiko, P.; Mateos, X.; Serres, J.M.; Ren, J.; Guo, J.; Cheng, R.; Gao, C.; Dong, Q.; Jambunathan, V.; et al. Crystal growth, low-temperature spectroscopy and multi-watt laser operation of $\mathrm{Yb}: \mathrm{Ca}_{3} \mathrm{NbGa}_{3} \mathrm{Si}_{2} \mathrm{O}_{14}$. J. Lumin. 2018, 197, 90-97. [CrossRef]

43. Sharma, G.S.; Faverjon, B.; Dureisseix, D.; Skvortsov, A.; MacGillivray, I.; Audoly, C.; Kessissoglou, N. Acoustic performance of a periodically voided viscoelastic medium with uncertainty in design parameters. J. Vib. Acoust. 2020, 142, 061002. [CrossRef]

44. Fabro, A.T.; Meng, H.; Chronopoulos, D. Uncertainties in the attenuation performance of a multi-frequency metastructure from additive manufacturing. Mech. Syst. Signal. Pr. 2020, 138, 106557. [CrossRef] 
45. Hou, Z.; Wu, F.; Liu, Y. Phononic crystals containing piezoelectric material. Solid State Commun. 2004, 130, 745-749. [CrossRef]

46. Zouari, S.; Brocail, J.; Génevaux, J.-M. Flexural wave band gaps in metamaterial plates: A numerical and experimental study from infinite to finite models. J. Sound Vib. 2018, 435, 246-263. [CrossRef] 